\title{
Effect of iloprost inhalation on postoperative outcome in high-risk cardiac surgical patients: a prospective randomized-controlled multicentre trial (ILOCARD)
}

\section{Effet de l'inhalation d'iloprost sur le pronostic postopératoire chez les patients chirurgicaux cardiaques à haut risque : une étude multicentrique randomisée et prospective (ILOCARD)}

\author{
Michael Winterhalter, MD • Steffen Rex, MD (i) - Christian Stoppe, MD • Peter Kienbaum, MD • \\ Hans-Helge Müller, PhD • Ines Kaufmann, MD • Hermann Kuppe, MD • Aristidis Dongas, MD • \\ Bernhard Zwissler, MD on behalf of ILOCARD Investigators
}

Received: 18 October 2018/Revised: 27 December 2018/Accepted: 28 December 2018/Published online: 12 February 2019

(C) Canadian Anesthesiologists' Society 2019

\begin{abstract}
Purpose Perioperative right ventricular (RV) failure due to pressure overload from pulmonary hypertension $(\mathrm{PH})$ worsens postoperative outcomes after cardiac surgery. Inhaled iloprost is a potent pulmonary vasodilator improving $R V$ performance, ameliorating myocardial and pulmonary ischemia-reperfusion injury and attenuating
\end{abstract}

Michael Winterhalter and Steffen Rex have contributed equally to this manuscript.

Part of the trial results were presented as an oral presentation at the Scientific Sessions of the American Heart Association in New Orleans, November $2016 .{ }^{1}$

Electronic supplementary material The online version of this article (https://doi.org/10.1007/s12630-019-01309-8) contains supplementary material, which is available to authorized users.

M. Winterhalter, MD

Klinik für Anästhesiologie und Schmerztherapie, Klinikum

Bremen-Mitte gGmbH, Bremen, Germany

Klinik für Anästhesiologie, Universitätsklinikum Düsseldorf, Düsseldorf, Germany

S. Rex, MD (ه)

Department of Anesthesiology \& Department of Cardiovascular Sciences, University Hospitals Leuven, KU Leuven, Herestraat 49, 3000 Leuven, Belgium

e-mail: steffen.rex@gmail.com

Klinik für Anästhesiologie, Universitätsklinikum der RWTH Aachen, Aachen, Germany inflammation. We hypothesized that the prophylactic inhalation of iloprost would reduce postoperative ventilation times after cardiac surgery.

Methods In this phase III, multicentre, randomized, double-blind, placebo-controlled trial, we randomly assigned 253 cardiac surgical patients at high risk of perioperative $R V$ failure to the prophylactic inhalation of $20 \mu \mathrm{g}$ iloprost or placebo before and during weaning from extracorporeal circulation. The primary endpoint was the duration of postoperative ventilation. Secondary endpoints included perioperative hemodynamics, intensive care unit and hospital length of stay, and 90-day mortality. Safety was assessed by the incidence of adverse events.

Results Iloprost had no significant effect on the median [interquartile range] duration of postoperative ventilation compared with placebo (720 [470-1170] min vs 778 [5411219] min, respectively; median decrease, $65 \mathrm{~min}$; 95\% confidence interval [CI], -77 to 210; $P=0.37$ ). While the

C. Stoppe, MD

Klinik für Anästhesiologie, Universitätsklinikum der RWTH Aachen, Aachen, Germany

P. Kienbaum, MD

Klinik für Anästhesiologie, Universitätsklinikum Düsseldorf, Düsseldorf, Germany

H.-H. Müller, PhD

Klinische Forschung, IBE - Institut für Medizinische

Informationsverarbeitung, Biometrie und Epidemiologie,

Ludwig-Maximilians-Universität München, Munich, Germany 
nebulization of iloprost decreased $R V$ afterload and improved cardiac index, major secondary endpoints were not significantly affected. Ninety-day mortality occurred in $14 \%$ of the iloprost patients compared with $14 \%$ of the placebo patients (hazard ratio, 0.97; 95\% CI, 0.50 to 1.89; $P=0.93)$. The incidence of adverse events was comparable in both groups.

Conclusions The prophylactic inhalation of iloprost did not meaningfully improve the outcome in high-risk cardiac surgical patients.

Trial registration $w w w . c l i n i c a l t r i a l s . g o v(N C T 00927654)$; registered 25 June, 2009.

\section{Résumé}

Objectif L'insuffisance cardiaque droite périopératoire due à une surcharge de pression provoquée par l'hypertension pulmonaire (HP) a un impact négatif sur le pronostic postopératoire après une chirurgie cardiaque. L'iloprost administré par inhalation est un vasodilatateur pulmonaire puissant qui améliore la performance du ventricule droit (VD), réduisant ainsi la lésion d'ischémie-reperfusion myocardique et pulmonaire et atténuant l'inflammation. Nous avons émis l'hypothèse qu'une inhalation prophylactique d'iloprost réduirait les temps de ventilation postopératoire après une chirurgie cardiaque.

Méthode Dans cette étude multicentrique de phase III, contrôlée par placebo, à double insu et randomisée, nous

Institut für Medizinische Biometrie und Epidemiologie,

Philipps-Universität Marburg, Marburg, Germany

I. Kaufmann, MD

Klinik für Anästhesiologie, LMU Klinikum der Universität München, Munich, Germany

Klinik für Anästhesiologie, Operative Intensivmedizin und Schmerztherapie, Städtisches Klinikum München, Neuperlach, Munich, Germany

H. Kuppe, MD

Institut für Anästhesiologie, Deutsches Herzzentrum Berlin, Berlin, Germany

\section{A. Dongas, MD \\ Institut für Anästhesiologie, Herz- und Diabeteszentrum NRW, Ruhr-Universität Bochum, Bad Oeynhausen, Germany}

Klinik für Anästhesiologie und operative Intensivmedizin, Franziskus Hospital Bielefeld, Bielefeld, Germany

B. Zwissler, MD

Klinik für Anästhesiologie, LMU Klinikum der Universität München, Munich, Germany avons distribué aléatoirement 253 patients chirurgicaux courant un risque élevé d'insuffisance cardiaque droite périopératoire à une prophylaxie de $20 \mu \mathrm{g}$ d'iloprost ou d'un placebo par inhalation avant et pendant le sevrage de la circulation extracorporelle. Le critère d'évaluation principal était la durée de ventilation postopératoire. Les critères d'évaluation secondaires étaient les données hémodynamiques périopératoires, la durée de séjour à l'unité de soins intensifs et à l'hôpital, et la mortalité à 90 jours. L'innocuité a été évaluée en fonction de l'incidence d'événements indésirables.

Résultats L'iloprost n'a pas eu d'effet significatif sur la durée médiane [écart interquartile] de ventilation postopératoire par rapport au placebo (720 [470-1170] min vs 778 [541-1219] min, respectivement; réduction médiane, 65 min; intervalle de confiance [IC] $95 \%$, - 77 à 210; $P=0,37)$. Bien que la nébulisation d'iloprost ait réduit la post-charge du VD et amélioré l'index cardiaque, cette manouvre n'a pas eu d'impact significatif sur les critères d'évaluation secondaires majeurs. Une mortalité à 90 jours a été observée chez $14 \%$ des patients ayant reçu de l'iloprost, comparativement à $14 \%$ des patients ayant reçu un placebo (rapport de risque, 0,97; IC $95 \%, 0,50$ à 1,89; $P=0,93)$. L'incidence d'événements indésirables était comparable dans les deux groupes.

Conclusion L'inhalation prophylactique d'iloprost n'a pas amélioré le pronostic des patients de chirurgie cardiaque à haut risque.

Enregistrement de l'étude $w w w$.clinicaltrials.gov (NCT00927654); enregistrée le 25 juin 2009.

Cardiac surgery with the use of extracorporeal circulation (ECC) elicits a systemic inflammatory response that is triggered by contact of blood with non-endothelial surfaces, cardiopulmonary ischemia-reperfusion injury, endotoxemia, and surgical trauma. ${ }^{2}$ Systemic inflammation is associated with pulmonary artery (PA) endothelial dysfunction. ${ }^{3}$ After termination of ECC, an increased release of vasoconstrictory endothelin and a decreased production of vasodilatory nitric oxide (NO) was found to be correlated with significant increases in pulmonary vascular tone. ${ }^{4,5}$ Perioperative increases in pulmonary vascular resistance result in acute new-onset or acute-on-chronic pulmonary hypertension $(\mathrm{PH})$, which are usually not well tolerated by the right ventricle. If the increase in right ventricular (RV) afterload continues or is aggravated, the right ventricle will eventually fail and initiate a self-aggravating cascade of circulatory shock. In fact, RV dysfunction has been repeatedly shown to dramatically worsen the outcome after cardiac surgery. ${ }^{6-8}$ 
One strategy for the therapy of perioperative RV dysfunction is to lower RV afterload with intravenously administered vasodilators, which lack pulmonary selectivity $^{9}$ and may perpetuate a vicious cycle of hypotension, leftward septal shift, RV ischemia, and shock. ${ }^{10}$ In contrast, selective pulmonary vasodilation can be achieved by inhalation of vasodilators. ${ }^{11}$ While this strategy was proven to improve systemic and pulmonary hemodynamics, beneficial effects on "harder" outcome parameters have not been shown yet, partly due to the lack of adequately powered studies with morbidity and/or mortality as the primary outcome. ${ }^{12}$

Because it is easy to administer and is not toxic, intermittent nebulization of iloprost has become increasingly popular in the treatment of postcardiotomy RV dysfunction. 9,13,14 Iloprost, the stable carbacyclin derivative of prostacyclin $\left(\mathrm{PGI}_{2}\right)$, is a potent pulmonary vasodilator that lowers RV afterload at least as effectively as inhaled NO. ${ }^{15}$ Moreover, iloprost and $\mathrm{PGI}_{2}$ improved biventricular performance, ${ }^{16-18}$ exerted anti-inflammatory effects, ${ }^{19}$ ameliorated myocardial ischemia-reperfusion injury, $^{20}$ improved oxygenation in adult respiratory distress syndrome, ${ }^{21}$ attenuated pulmonary ischemiareperfusion injury, ${ }^{22}$ improved the pulmonary clearance of endothelin, ${ }^{23}$ and reduced oxidative stress and counteracted platelet activation with consecutive microthrombosis. $^{24}$

On the background of these beneficial effects, we hypothesized that the prophylactic inhalation of iloprost would improve perioperative morbidity and outcome in patients undergoing elective heart surgery with ECC and at an increased risk for perioperative RV failure. The primary outcome parameter considered was the duration of postoperative ventilation, which we considered as a surrogate parameter for the severity of critical illness in cardiac surgical patients and is prolonged by $\mathrm{PH}, \mathrm{RV}$ failure, shock, and prolonged ECC times. ${ }^{25-27}$

\section{Methods}

Trial design and population

The "Effect of ILOprost inhalation before and during EEC on perioperative morbidity and outcome in high-risk CARDiac surgical patients" (ILOCARD) study was a prospective, multicentre, randomized, double-blind, placebo-controlled, phase III trial, conducted in six German heart centres. It was approved by the local ethics committee of each participating institution (leading ethics committee: ethics committee of the Medical Faculty of the LMU München, project number 419-08, January 28, 2009) and by Germany's Federal Institute for Drugs and Medical
Devices (BfArM, 4034768, March 4, 2009). The trial was registered prior to patient enrollment at clinicaltrials.gov (NCT00927654, Principal investigator: B. Zwissler, Date of registration: June 25, 2009) and at the EU clinical trials register (EudraCT 2008002090-12, Date: March 4, 2009). Note that iloprost is not labelled for clinical use under investigation in this trial.

Written informed consent was obtained from all patients. We enrolled patients $\geq 18$ and $\leq 85 \mathrm{yr}$ of age scheduled for elective open-heart surgery with the assistance of ECC and with an increased risk of perioperative RV failure. The latter was assumed by 1) the necessity to undergo complex cardiac surgery (surgery on $\geq 2$ valves or expected duration of ECC $>120 \mathrm{~min}$ ), or 2) the presence of preoperative $\mathrm{PH}$ (mean pulmonary arterial pressure $[\mathrm{mPAP}]>30 \mathrm{mmHg}$ measured by $\mathrm{RV}$ catheterization or a systolic PAP $\geq 60 \mathrm{mmHg}$ measured by echocardiography at screening), or 3) the presence of congestive heart failure (New York Heart Association [NYHA] class $\geq$ III). ${ }^{6}$ Patients were excluded if they had known hypersensitivity to iloprost or other prostaglandins, were pregnant or breastfeeding, suffered from primary or secondary immune deficiency or an acute systemic infection, had lung disease with impaired gas exchange (partial pressure of oxygen $\left[\mathrm{PaO}_{2}\right]<60 \mathrm{mmHg}$ at the fraction of inspired oxygen $\left[\mathrm{F}_{\mathrm{I}} \mathrm{O}_{2}\right]$ of $0.21 \mathrm{mmHg}$ ), had a hemorrhagic diathesis, thrombocytopenia $<50,000 / \mu$ or other coagulation disorders, suffered from recent trauma, current ulcer, intracerebral hemorrhage or stroke $(<$ three months ago), or were scheduled for lung transplantation, heart transplantation, left ventricular assist device implantation or for deep hypothermic cardiocirculatory arrest. Female patients of childbearing potential were required to use a reliable method of contraception.

\section{Randomization/allocation and concealment/blinding}

Patients were randomized using a computer-generated permuted block randomization sequence (block size 6, 1:1 allocation). Randomization was stratified by centre and by dichotomizing the major prognostic score of the European System for Cardiac Operative Risk Evaluation (EuroSCORE) using a cutoff of 10 (Stratum I: EuroSCORE $\leq 10$; Stratum II: EuroSCORE $>10$ ). Study drugs were sealed in sequentially numbered identical containers that were provided to the participating centres in balanced blocks according to the allocation sequence. The study medication was prepared by an independent operator not otherwise involved in the trial (Pharmacy of the Heidelberg University Hospital, Heidelberg, Germany). Iloprost and placebo medication were identical in colour, appearance, shape, and size. All investigators were blinded to treatment allocation throughout the entire study, including the data 
management and the trial statistician until the completion of a blinded data review meeting.

\section{Intervention}

Participating patients were 1:1 randomized to the inhalation of $20 \mu \mathrm{g}$ iloprost $\left(2 \mathrm{~mL}\right.$ Ventavis ${ }^{\circledR}$, Bayer Vital GmbH, Leverkusen, Germany) or $2 \mathrm{~mL}$ placebo (saline $0.9 \%$, B Braun Melsungen AG, Melsungen, Germany) twice, immediately prior to the start of ECC (to test the hypothesis that iloprost would counteract ECCinduced pulmonary inflammation) and after release of the aortic cross-clamp (before weaning from ECC). Study drugs were administered over a time period of five to ten minutes via an electronic micropump nebulizer using vibrating mesh nebulization technology (Aeroneb@ Solo, Aerogen Ltd., Galway, Ireland). This nebulizer delivers particles with a mass median aerodynamic diameter of 3.4 $\mu \mathrm{m}$.

\section{Perioperative management}

Intraoperative anesthesia, perioperative hemodynamic treatment, coagulation therapy, and intensive care unit (ICU) management were performed according to the institutional standards of the participating centres. The patients received standard cardiorespiratory monitoring plus pulmonary arterial catheterization.

Prior to and after ECC, all patients were ventilated using pressure-controlled ventilation and maintaining normocapnia. Before weaning from ECC and the second study drug inhalation, a manual recruitment maneuver was performed with subsequent adjustment of positive end-expiratory pressure (PEEP). During weaning from EEC, patients were ventilated with $100 \%$ oxygen.

After completion of surgery, patients were transferred to the ICU.

\section{Extubation protocol in the ICU}

After admission to the ICU, patients were sedated with a continuous infusion of propofol $\left(3-5 \mathrm{mg} \cdot \mathrm{kg}^{-1} \cdot \mathrm{hr}^{-1}\right.$ ) and a pre-defined extubation protocol was applied. Sedation was stopped once the patient was hemodynamically stable, normothermic (core temperature $>36^{\circ} \mathrm{C}$ ) and pulmonary gas exchange was sufficient $\left(\mathrm{F}_{\mathrm{I}} \mathrm{O}_{2}<50 \%\right.$, PEEP $<10$ $\mathrm{cmH}_{2} \mathrm{O}, \mathrm{PaO}_{2}>90 \mathrm{mmHg}$ ). Patients were considered to be suitable for extubation once they were awake and responsive to verbal stimuli, were hemodynamically stable, had no significant blood loss $\left(<100 \mathrm{~mL} \cdot \mathrm{hr}^{-1}\right.$ via the chest drains), and accomplished the following ventilatory parameters: $\mathrm{F}_{\mathrm{I}} \mathrm{O}_{2}<45 \%$, $\mathrm{PEEP}<10 \mathrm{cmH}_{2} \mathrm{O}$,
$\mathrm{PaO}_{2}>90 \mathrm{mmHg}$, spontaneous respiratory rate $>10 / \mathrm{min}$, and spontaneous respiratory minute volume $75-150$ $\left.\mathrm{mL} \cdot \mathrm{kg}^{-1}\right)$.

Trial endpoints

\section{Efficacy endpoints}

The primary efficacy endpoint was the duration of postoperative ventilation (defined as the time between admission to the ICU and protocol-guided extubation, or as the time between ICU admission and death if the patient died before extubation).

Secondary efficacy endpoints included incidence of failure to wean from ECC (defined as the requirement for multiple weaning attempts with the weaning protocol left at the discretion of the study centre); incidence of RV failure $30 \mathrm{~min}$ after termination of ECC and during the first $24 \mathrm{hr}$ postoperatively (diagnosed by the combination of a sudden increase in central venous pressure in excess of PA occlusion pressure, typical echocardiographic criteria [RV end-diastolic area $>$ left ventricular end-diastolic area], and/or direct visual inspection intraoperatively); incidence of PH (mean PAP > $25 \mathrm{mmHg}$ ) $30 \mathrm{~min}$ after end of ECC and six hours postoperatively; incidence of acute hypoxemic respiratory failure $\left(\mathrm{PaO}_{2} / \mathrm{F}_{\mathrm{I}} \mathrm{O}_{2}<300 \mathrm{mmHg}\right)$ $30 \mathrm{~min}$ after end of ECC and six hours postoperatively; systemic and pulmonary hemodynamics after induction of anesthesia, $30 \mathrm{~min}$ after end of ECC, one hour and six to 12 hr after admission to the ICU; requirement to use vasopressors, inotropes, and other rescue medication six hours postoperatively (left at the discretion of the attending investigator); perioperative systemic inflammation (plasma levels of interleukin [IL]-6 and tumour necrosis factor $[\mathrm{TNF}]-\alpha$ obtained after induction of anesthesia and six to $12 \mathrm{hr}$ after ICU admission); postoperative pulmonary inflammation (levels of IL- 6 and TNF- $\alpha$ determined from bronchoalveolar lavage [BAL] fluid six to $12 \mathrm{hr}$ after ICU admission, using enzyme-linked immunosorbent assays); ICU and hospital length of stay; and 90-day mortality.

\section{Exploratory endpoints}

Arterial serum levels of iloprost were also measured (for analytical details, see electronic supplemental material [ESM]).

\section{Safety endpoints}

Safety endpoints measured included the incidence of rethoracotomy for bleeding, incidence of intracranial 
hemorrhage, stroke, and pneumonia, and the incidence of other (serious) adverse events.

Sample size estimation

Sample size determination was based on testing the primary endpoint for differences at a two-sided type I error level of $5 \%$ (2.5\% each for superiority and inferiority) using the non-parametric Wilcoxon-Mann-Whitney test. According to the experience of the participating centres and following the published literature, ${ }^{28,29}$ we expected a mean time of $24 \mathrm{hr}$ postoperative ventilation in survivors from the high-risk study population. Assuming a standard deviation of $16 \mathrm{hr}$ and a mortality of $10 \%$, we calculated that in case of equal group size, 124 patients per group were needed to detect a seven-hour reduction in the time of postoperative ventilation with a power of $80 \%$. Coping with slight imbalances of the group sizes at random, we aimed to randomize until at least 250 patients could be included in the statistical analysis.

\section{Statistical analysis}

Analyses were performed with SAS, versions 9.3 and 9.4 (SAS Institute, Cary, NC, USA), StatXact of Cytel Studio, version 6.3.0 (Cytel Studio; Cytel Corporation, Cambridge, MA, USA), and the R Project for Statistical Computing. All analyses were conducted primarily on an intention to treat (ITT) basis. The primary endpoint was compared between the two groups using the Wilcoxon-MannWhitney test. Thereby, patients dying before extubation were assessed with worst ranks, using the hierarchical order "worse when dying during surgery than after admission to ICU" in general, and "worse when dying early" for the two time periods in which death could occur (intraoperatively $v s$ during ICU stay). The pre-defined primary test adjusts for risk strata I and II, i.e., for EuroSCORE $\leq />10$. Confidence intervals (CIs) for the location shift were calculated using the method of Hodges and Lehmann. Moreover, to verify the robustness of the result, sensitivity analyses were performed using per protocol sets, using a linear regression model with the rank as dependent variable (adjusting for age, sex, and EuroSCORE), and by modelling competing risks with an analysis of cause-specific hazards (adjusted for the identical factors). In addition, the treatment effect was calculated separately for both risk strata. For the analysis of the secondary endpoints and the exploratory analyses, continuous variables were tested using the WilcoxonMann-Whitney test. Categorical variables were compared using the Fisher's exact test. Time-to-event outcomes were described with the Kaplan-Meier technique, and the treatment effect was compared between the two groups using a log-rank test. The treatment effect is reported in hazard ratios (HR) that were derived from a Cox regression. All endpoints were analyzed both unstratified (unadjusted) and stratified (adjusted) for the EuroSCORE $\leq$ or $>10$.

All endpoints and statistical methodology were defined before unblinding, except for the post hoc exploratory subgroup analyses and analyses of the hemodynamic parameters. For the latter, we performed an explanatory intergroup comparison six to $12 \mathrm{hr}$ after admission to the ICU (T5). In addition, hemodynamic parameters were modelled over time assuming that the parameters are normally distributed. Results of linear mixed models with treatment and time (factor with repeated measurements at $\mathrm{T} 2, \mathrm{~T} 3, \mathrm{~T} 4$, and $\mathrm{T} 5$, i.e., just prior to and $30 \mathrm{~min}$ after end of ECC, one hour and six to $12 \mathrm{hr}$ after admission to the ICU, respectively) as fixed effects and the baseline parameter value after induction of anesthesia (T1) as covariable were provided.

All reported $P$ values are two-sided.

\section{Results}

Patients

From June 16, 2009 to December 12, 2011, 253 patients were enrolled. Of these patients, 122 were randomized to receive placebo, and 131 were assigned to receive iloprost (Fig. 1). One patient in the iloprost group withdrew informed consent for surgery after enrollment into the study, thus underwent neither surgery nor anesthesia and could not be evaluated for the primary endpoint. Therefore, the ITT population consisted of 252 patients. Baseline characteristics of the patients are depicted in Table 1.

\section{Primary efficacy endpoint}

Groups did not differ significantly with respect to median [interquartile range (IQR)] duration of postoperative ventilation (720 [470-1170] min iloprost vs 778 [5411219] min placebo; median decrease [Hodges-Lehmann], $65 \mathrm{~min}$; 95\% CI, -77 to $210 \mathrm{~min}$; unadjusted $P=0.37$ ) (Fig. 2, Table 2). In a pre-planned post hoc analysis and according to the prognostic relevance, the primary analysis was adjusted for the EuroSCORE by stratification (increase EuroSCORE stratum II $v s$ stratum I, 355 min, $P<0.001$ ). Iloprost similarly did not significantly reduce the duration of postoperative ventilation (Hodges-Lehmann decrease) in stratum I by $35 \mathrm{~min}(95 \% \mathrm{CI},-115$ to 179$)$ or in stratum II by $180 \mathrm{~min}$ ( $95 \% \mathrm{CI},-315$ to 715 ). 


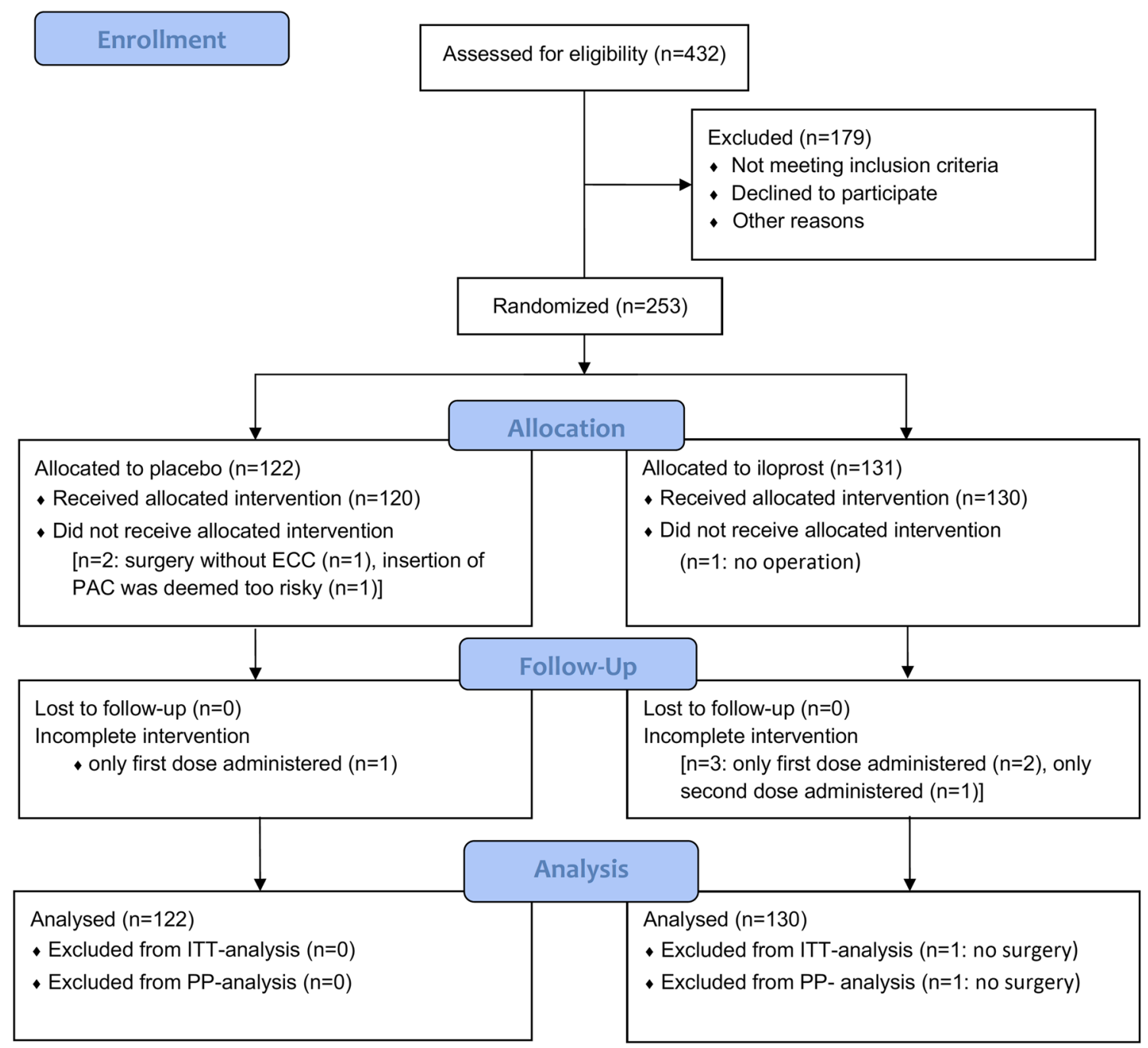

Fig. 1 Flow diagram presenting enrollment, intervention allocation, follow-up and data analysis. ITT = intention to treat; PAC = pulmonary artery catheter; $\mathrm{PP}=$ per protocol

Table 1 Clinical characteristics of the patients at baseline

\begin{tabular}{llll}
\hline & & Placebo $(n=122)$ & Iloprost $(n=131)$ \\
\hline Age & $\mathrm{y}$ & $73.3[67.1-78.0]$ & $72.6[65.0-76.5]$ \\
Sex: male/female & $n(\%)$ & $70 / 52(57 / 43)$ & $73 / 58(56 / 44)$ \\
BMI & $\mathrm{kg} \cdot \mathrm{m}^{-2}$ & $26.3[23.8-29.0]$ & $26.4[23.6-30.1]$ \\
EuroSCORE I & & $9[7-11]$ & $9[7-11]$ \\
Stratum I/II & $n(\%)$ & $90 / 32(74 / 26)$ & $97 / 34(74 / 26)$ \\
LVEF & $\%$ & $49[35-60]$ & $45[35-60]$ \\
NYHA class I/II/III/IV & $n(\%)$ & $8 / 35 / 75 / 4(7 / 29 / 61 / 3)$ & $8 / 32 / 84 / 5(6 / 25 / 65 / 4)$ \\
Valvular heart disease & $n(\%)$ & $117(96)$ & $123(94)$ \\
Ischemic heart disease & $n(\%)$ & $80(66)$ & $80(62)$ \\
Pulmonary hypertension & $n(\%)$ & $75(62)$ & $72(55)$
\end{tabular}

Data are presented as median [interquartile range] or as absolute numbers (with the $\%$ of the patients within each group)

BMI = body mass index, EuroSCORE = European System for Cardiac Operative Risk Evaluation, LVEF = left ventricular ejection fraction, NYHA $=$ New York Heart Association, Stratum I: EuroSCORE $\leq 10$, Stratum II: EuroSCORE $>10$ 


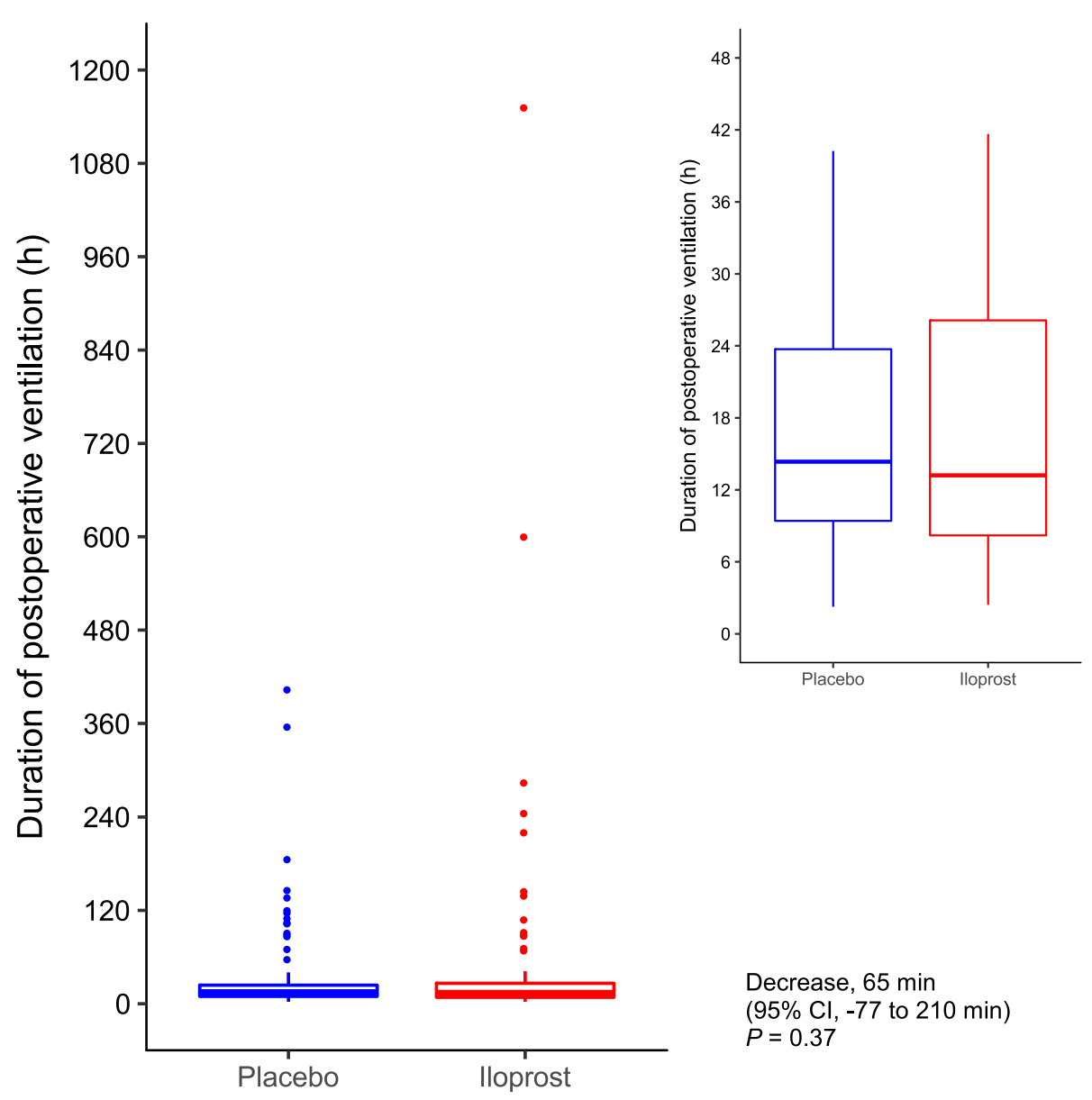

Fig. 2 Comparing the distribution of the primary endpoint "duration of postoperative ventilation" in high-risk cardiac surgical patients receiving inhaled iloprost or placebo twice during cardiac surgery. The distribution was compared between both groups using the Wilcoxon-Mann-Whitney test and the Hodges-Lehmann estimator for the location shift. Adjusting for the EuroSCORE by stratification ( $\leq$ or $>10$ ), the exact $P$-value and estimate of decrease by iloprost with 95\% confidence interval are provided. Thereby, patients dying before regular extubation were assessed with worst ranks, using the hierarchical order "worse when dying during surgery than after admission to intensive care unit (ICU)" in general, and "worse when dying early" for the two time periods in which death could occur

\section{Secondary efficacy endpoints}

Groups did not differ with respect to the majority of secondary efficacy endpoints (Table 2), neither in the unadjusted nor in the stratified analysis (adjusted results not always shown).

Ninety-day mortality occurred in 18 iloprost patients (14\%; 95\% CI, 8 to 20) compared with 16 placebo patients (14\%; 95\% CI, 7 to 20) (unadjusted HR, 0.97; 95\% CI, 0.50 to $1.88 ; P=0.92$; HR EuroSCORE stratum II $v s$ stratum I, 3.23; $P<0.001$; adjusted HR, 0.97; 95\% CI, 0.50 to $1.89, P=0.93$ ) (Fig. 3). (intraoperatively $v s$ during ICU stay). The lower hinge of the box indicates the 25th percentile, the line within the box marks the median, and the upper hinge of the box indicates the 75th percentile. Whiskers extend from the lower and the upper hinge up to the lowest and the highest value within 1.5 times the interquartile range lower and higher than the hinge, respectively, while closed circles represent outliers. The iloprost group consists of 112 values plus ten worst ranks, the placebo group of 121 values plus nine worst ranks. The inlay shows a magnification of the main figure without displaying the outliers (note that they were still included in the calculation of the percentiles)

Failure to wean from ECC occurred in $3(2.3 \%)$ of the patients in the iloprost group $v s 9(7.5 \%)$ in the placebo group (odds ratio, $0.29 ; 95 \% \mathrm{CI}, 0.050$ to $1.22 ; P=0.08$ ).

\section{PERIOPERATIVE HEMODYNAMICS}

Overall, the inhalation of iloprost significantly increased the cardiac index, and decreased systemic and pulmonary vascular resistance indices. Nevertheless, these differences were not sustained as the separate analysis of the intergroup comparison six hours after admission to the ICU failed to show any significant differences (Table 3). 
Table 2 Efficacy outcomes

Placebo $(n=122)$

Primary endpoint

Duration of postop. ventilation

Secondary endpoints

ICU length of stay

Hospital length of stay

Failure to wean from ECC

RVF at end of ECC

RVF 24 hr postop.

$\mathrm{PH}$ after sternal closure

PH $6 \mathrm{hr}$ postop.

ALI at end of ECC

ALI 1 hr postop.

ALI 6 hr postop.

Use of rescue medication

$\begin{array}{llll}\text { Dobutamine } & n(\%) & 65(53.3) & 58(44.6) \\ \text { Epinephrine } & n(\%) & 58(47.5) & 58(44.6) \\ \text { Norepinephrine } & n(\%) & 104(85.2) & 116(89.2) \\ \text { Milrinone } & n(\%) & 46(37.7) & 46(35.4) \\ \text { iNO } & n(\%) & 6(4.9) & 8(6.2) \\ \text { Iloprost } & n(\%) & 19(15.6) & 21(16.2)\end{array}$

Deaths before extubation

$\begin{array}{lll}12.0[7.8-19.5]^{* *} & 1.08(-1.28 \text { to } 3.50)^{* * *} & 0.37^{* * *} \\ 9(6.9) & 0.83(0.29 \text { to } 2.38) & 0.81 \\ 4[2-7] & 0(-1 \text { to } 1) & 0.79 \\ 13[9-19] & 1(-1 \text { to } 3) & 0.35 \\ 3(2.3) & 0.29(0.050 \text { to } 1.22) & 0.08 \\ 6(4.7) & 0.68(0.19 \text { to } 2.33) & 0.40 \\ 7(5.5) & 0.80(0.24 \text { to } 2.61) & 0.78 \\ 74(60.7) & 0.88(0.50 \text { to } 1.55) & 0.69 \\ 81(71.1) & 1.25(0.67 \text { to } 2.30) & 0.47 \\ 71(56.8) & 0.82(0.48 \text { to } 1.42) & 0.51 \\ 65(52.0) & 1.01(0.59 \text { to } 1.73) & 1.00 \\ 53(49.1) & 1.25(0.70 \text { to } 2.23) & 0.49 \\ & & \\ 58(44.6) & 0.71(0.42 \text { to } 1.20) & 0.21 \\ 58(44.6) & 0.89(0.53 \text { to } 1.50) & 0.70 \\ 116(89.2) & 1.43(0.64 \text { to } 3.28) & 0.35 \\ 46(35.4) & 0.90(0.52 \text { to } 1.56) & 0.79 \\ 8(6.2) & 1.27(0.37 \text { to } 4.57) & 0.79 \\ 21(16.2) & 1.04(0.50 \text { to } 2.18) & 1.00\end{array}$

* Difference (italic letters): placebo minus iloprost $\dagger$ Odds ratio: iloprost $v s$ placebo

** Deaths before extubation not considered *** Deaths before extubation considered as worst ranks. Data are presented as median [first quartile, third quartile] or as absolute numbers (with the percentage (\%) of the patients within each group). Continuous variables were tested using the Wilcoxon-Mann-Whitney test. Categorical variables were compared by means of the Fisher's exact test. Confidence intervals were calculated using the method of Hodges and Lehmann. ALI = acute lung injury; ECC = extracorporeal circulation; $\mathrm{ICU}=$ intensive care unit; PH = pulmonary hypertension; postop. = postoperative; $\mathrm{RVF}=$ right ventricular failure
Fig. 3 Kaplan-Meier estimated postoperative mortality in highrisk cardiac surgical patients receiving inhaled iloprost or placebo twice during cardiac surgery. ECC = extracorporeal circulation

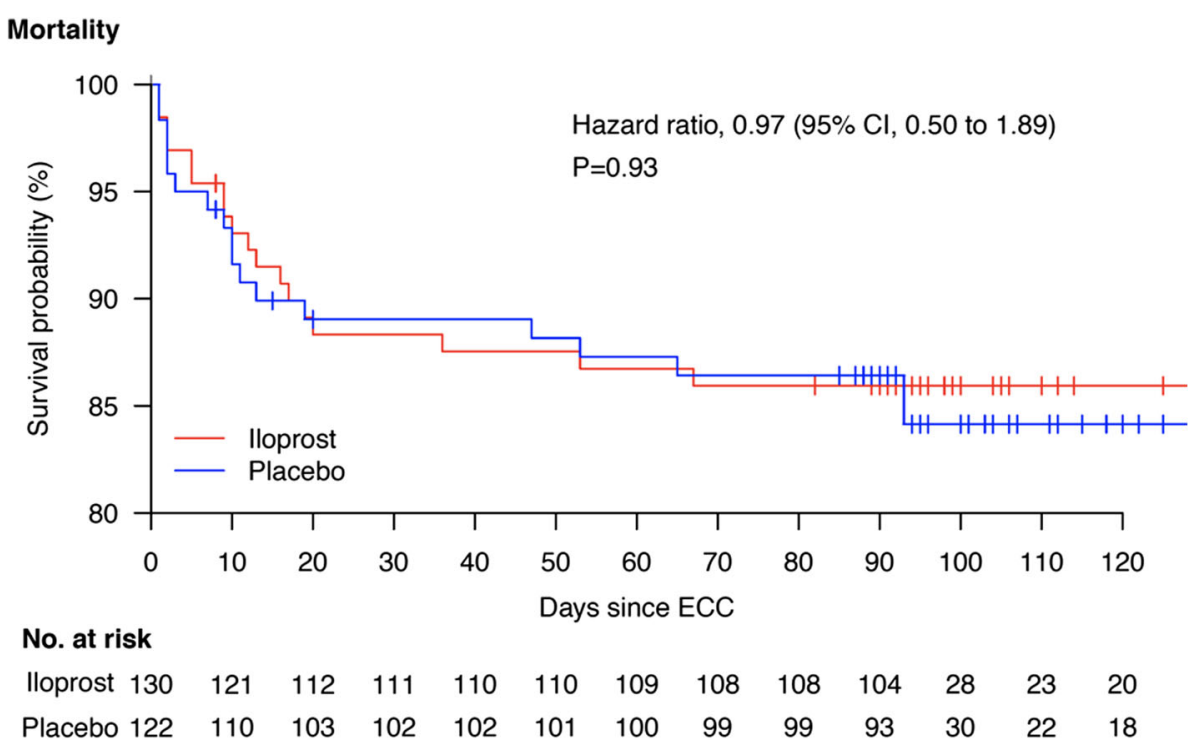




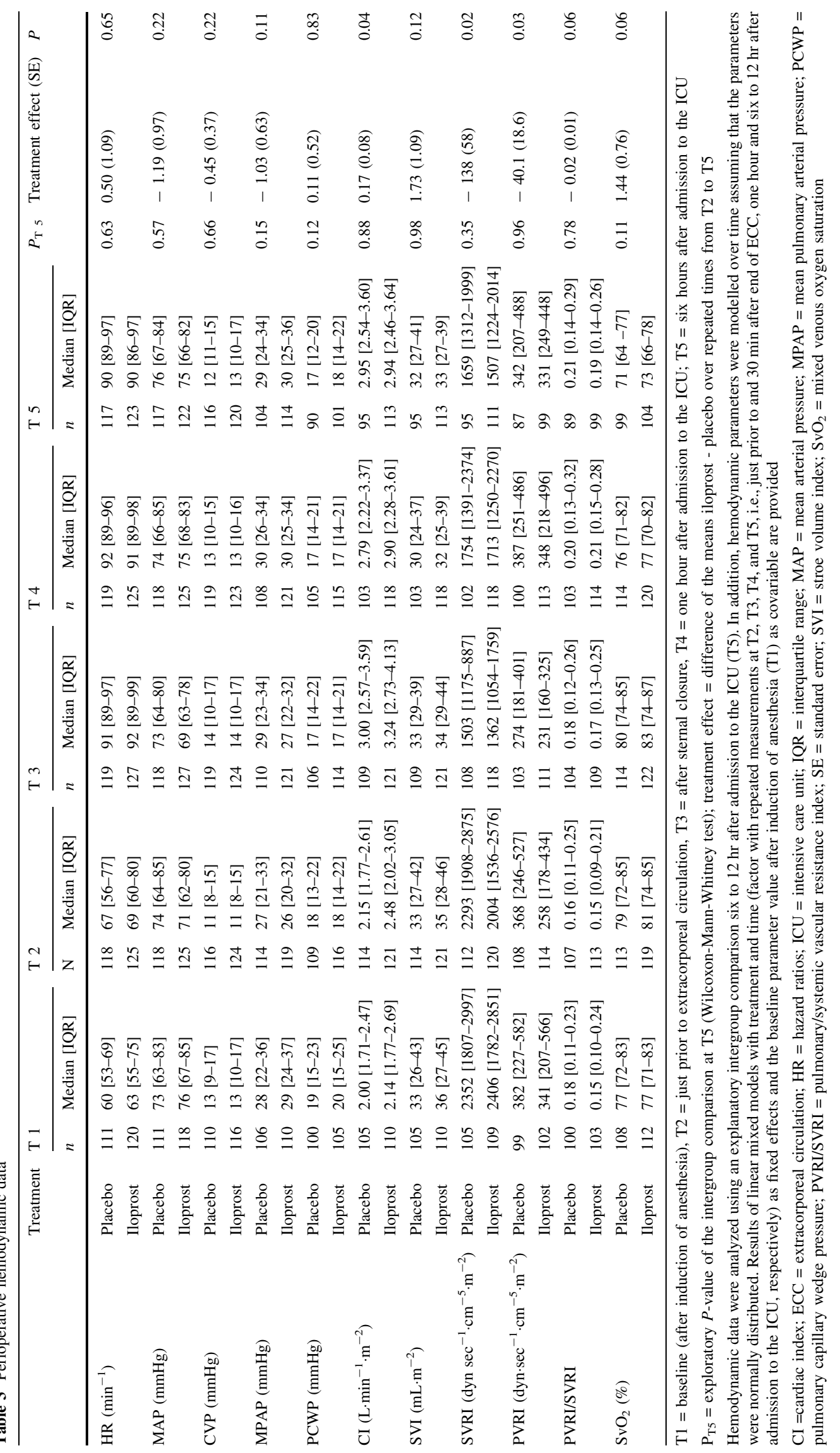



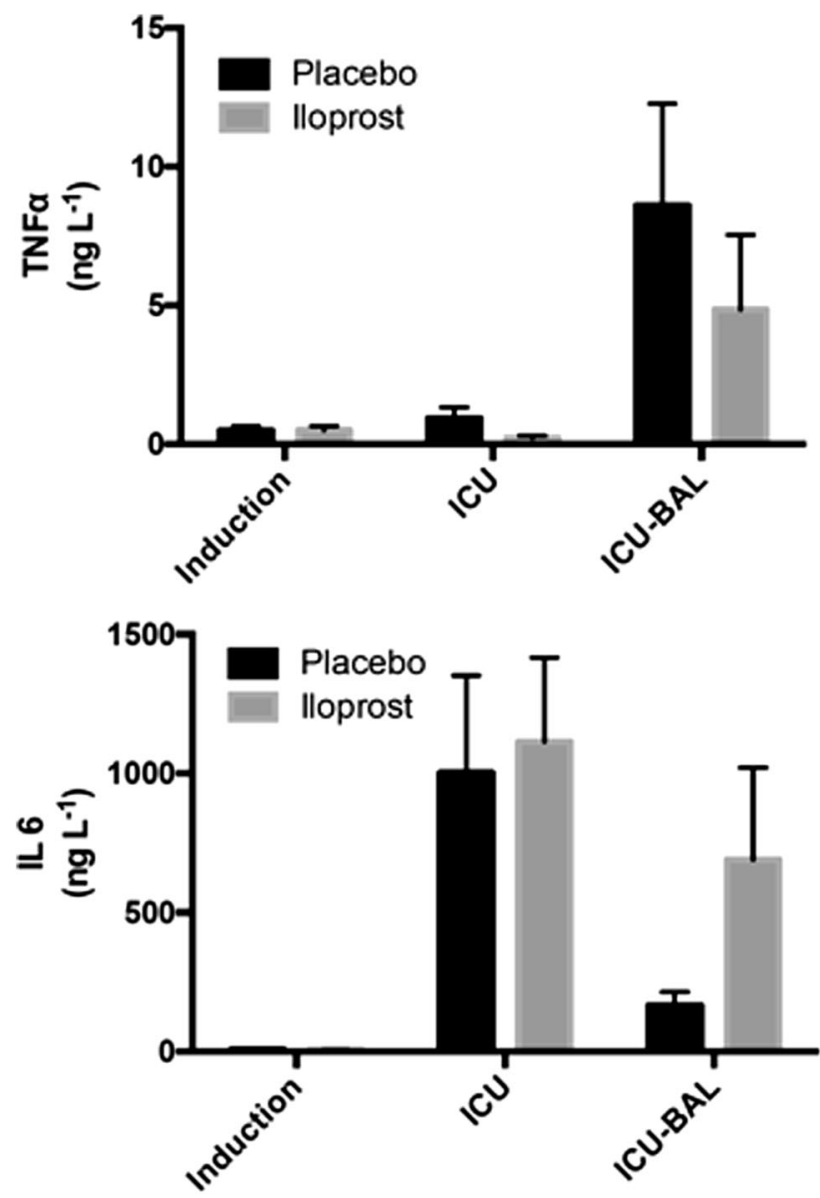

Fig. 4 Perioperative inflammatory profile as assessed by the serum concentration of tumour necrosis factor alpha (TNF- $\alpha$ ) and interleukin 6 (IL-6) after induction of anesthesia and six to $12 \mathrm{hr}$ after admission to the intensive care unit (ICU). Moreover, levels of IL-6 and TNF- $\alpha$ are shown that were determined in bronchoalveolar lavage (BAL) fluid (obtained with fibreoptic bronchoscopy six to $12 \mathrm{hr}$ after admission to the ICU). Data were available for 110 , 113, and 88 patients in the placebo group, and for 118, 114, and 91 patients in the iloprost group after anesthesia induction, after admission to the ICU and for BAL, respectively. Data are presented as means + SEM

\section{PERIOPERATIVE INFLAMMATION}

Serum and BAL levels of pro-inflammatory cytokines were available for 110,113 , and 88 patients in the placebo group, and for 118, 114, and 91 patients in the iloprost group after anesthesia induction, after admission to the ICU, and for BAL, respectively. These values were comparable in the two groups (Fig. 4).

\section{Safety endpoints}

Both groups had a comparable incidence of the four prespecified safety endpoints (Table 4). Likewise, the total number of all adverse events, deaths, and other serious adverse events did not differ significantly between groups.

Exploratory analyses

In the iloprost group, significantly more patients responded to the first inhalation with a decrease in mPAP of $\geq 20 \%$ than in the placebo group ( 38 vs $21, P=0.01$ ). In the subgroup of the responders, iloprost did not reduce ventilation times (observed change, $-85 \mathrm{~min}$; 95\% CI, - 285 to 620 ; unadjusted $P=0.68$; adjusted $P=0.70$ ).

Iloprost levels were determined in all 107 patients included in Düsseldorf ( $n=52$ receiving placebo, $n=55$ receiving iloprost). In the placebo patients, median [IQR] iloprost levels were below the detection limit, whereas the patients receiving iloprost had levels of 72 [52-111] $\mathrm{pg} \cdot \mathrm{mL}^{-1}$.

In the subgroup of patients in which the iloprost inhalation resulted in serum levels $\geq$ the median of all patients $(27 / 55=49 \%)$, ventilation times were significantly reduced by $253 \mathrm{~min}$ compared with the placebo group (95\% CI, -620 to $-5 ; P=0.045)$.

\section{Discussion}

In the present study, the prophylactic inhalation of iloprost failed to improve meaningful clinical outcomes in patients with an increased risk of perioperative RV failure undergoing elective open-heart surgery.

Up to now, this is one of the largest multicentre studies and one of the few prospective randomized-controlled trials addressing the perioperative management of $\mathrm{PH}$ and associated RV failure in cardiac surgery. We specifically included a high-risk population, illustrated by the baseline characteristics of the included patients and confirmed by an observed 90-day mortality of approximately $15 \%$.

Inhaled iloprost significantly improved systemic hemodynamics by reducing pulmonary vascular resistance and unloading the $\mathrm{RV}$ in patients with $\mathrm{PH}$ undergoing cardiac surgery. ${ }^{9,14}$ While these beneficial hemodynamic effects could be partly confirmed in the present study, they were subtle and did not translate into an improvement of any meaningful clinical outcome. This is in agreement with the findings of a recent meta-analysis in which the use of aerosolized vasodilators improved RV performance but was unable to affect major and clinically relevant outcomes. ${ }^{12}$

Several factors may have contributed to the documented lack of efficacy. First, the observed postoperative ventilation times were considerably shorter than anticipated. This was probably due to fundamental changes in clinical practice of the participating ICU's 
Table 4 Safety endpoints

\begin{tabular}{|c|c|c|c|c|}
\hline & & Placebo $(n=122)$ & Iloprost $(n=130)$ & $P$ value \\
\hline \multicolumn{5}{|l|}{ Pre-specified safety endpoints } \\
\hline Re-thoracotomy for bleeding & $n(\%)$ & $3(2.5)$ & $3(2.3)$ & 1.00 \\
\hline Intracranial hemorrhage & $n(\%)$ & $0(0.0)$ & $0(0.0)$ & 1.00 \\
\hline Ischemic stroke & $n(\%)$ & $4(3.3)$ & $4(3.1)$ & 1.00 \\
\hline Pneumonia & $n(\%)$ & $16(13.1)$ & $15(11.5)$ & 0.71 \\
\hline \multicolumn{5}{|l|}{ Adverse events } \\
\hline All adverse events & $n$ & 530 & 572 & n.a. \\
\hline Death & & & & 0.94 \\
\hline Intraoperative & $n(\%)$ & $0(0.0)$ & $1(0.8)$ & \\
\hline Before extubation & $n(\%)$ & $10(8.2)$ & $8(6.2)$ & \\
\hline After extubation & $n(\%)$ & $6(4.9)$ & $7(5.4)$ & \\
\hline After discharge & $n(\%)$ & $1(0.8)$ & $2(1.5)$ & \\
\hline \multicolumn{5}{|l|}{ Other serious adverse events } \\
\hline All* & $n$ & 94 & 113 & n.a. \\
\hline Cardiac & $n$ & 41 & 36 & n.a. \\
\hline Infections & $n$ & 12 & 21 & n.a. \\
\hline Respiratory & $n$ & 7 & 18 & n.a. \\
\hline Nervous system & $n$ & 10 & 11 & n.a. \\
\hline Others & $n$ & 24 & 27 & n.a. \\
\hline
\end{tabular}

*Without death

Data are presented as absolute numbers with the percentage (\%) of the patients within each group. Categorical variables were compared by means of the Fisher's exact test

n.a. = not available

since the observations upon which the power analysis was based had been made.

Second, the optimal dose of inhaled iloprost in the perioperative setting is still unknown. For the chronic treatment of $\mathrm{PH}$ in spontaneously breathing patients, doses of $2.5-5 \mu \mathrm{g} /$ inhalation are recommended. ${ }^{30}$ While exact dose-response relationships for iloprost in ventilated patients are not available, several authors reported significant hemodynamic effects for doses of 20-25 $\mu \mathrm{g}$ areosolized iloprost per inhalation. ${ }^{9,14}$ For inhaled milrinone, it has recently been shown that up to $60 \%$ of the initially nebulized dose is lost before it reaches the end of the endotracheal tube. ${ }^{31}$ We therefore opted for a dose of $20 \mu \mathrm{g}$ that was several times higher than the effective dose in spontaneously breathing patients and with which we obtained blood levels that have been reported to be in the therapeutic range. ${ }^{32}$ The dose of $20 \mu \mathrm{g}$ resulted in short-term hemodynamic improvements in our patients but was probably still too low to achieve sustainable effects. This is also suggested by the observation of significant effects in the subgroup of patients in which the iloprost inhalation resulted in higher than median blood levels. Future studies are needed to explore dose-response relationships in cardiac surgical patients in the perioperative setting.
Third, the "half-life" of pulmonary vasodilating effects is approximately $21-25 \mathrm{~min},{ }^{32}$ necessitating six to nine repetitive iloprost inhalations per day in the treatment of chronic $\mathrm{PH} .{ }^{30}$ This duration of action was likely too short to cover the entire time span of ECC and to obtain pharmacologic effects lasting beyond the immediate perioperative period. It remains unknown whether continuing iloprost nebulizations in the postoperative period would have resulted in more favourable outcomes.

Fourth, while the efficacy of inhaled iloprost has been proven in patients with pulmonary arterial hypertension and in chronic thromboembolic $\mathrm{PH}^{30}$ the vast majority of our patients suffered from $\mathrm{PH}$ due to left heart disease, i.e., secondary to systolic/diastolic left ventricular dysfunction and/or valvular disease. Pulmonary vasodilators increase pulmonary venous return, which can potentially overwhelm a failing ventricle. ${ }^{33}$ Nevertheless, pulmonary capillary wedge pressures in our study patients were not indicative for such a counterproductive mechanism, a finding recently reported also in medical patients with $\mathrm{PH}$ due to left heart failure. ${ }^{34}$

Fifth, although focusing on a high-risk population, the inclusion and exclusion criteria may have been too liberal (resulting in only $60 \%$ of the included patients suffering from $\mathrm{PH}$ and having a NYHA class $\geq$ III). Notably, 
iloprost appeared to have a greater effect in patients with a EuroSCORE $>10$. Further studies should therefore target patients with an extremely high surgical risk and poor functional state due to $\mathrm{PH}$.

Sixth, unbalanced pulmonary vasoconstriction is only one pathophysiologic mechanism contributing to post-ECC cardiopulmonary dysfunction. In cardiac surgery, numerous triggers of postoperative organ dysfunction have been identified in which prostacyclins have no or only an ancillary role, e.g., coronary hypoperfusion/ ischemia, systemic inflammatory response, valvular dysfunction, atelectasis, volume overload etc. Hence, reenforcing the $\mathrm{PGI}_{2}$ pathway by nebulization of iloprost would simply be unable to target all the various etiologies underlying prolonged ventilator dependency on ICU or other "hard" outcome parameters. Similar considerations have been brought forward to explain why, in two multicentre trials, neither endothelin blockade nor inhaled milrinone prevented $\mathrm{RV}$ failure in high-risk cardiac surgery, ${ }^{6,8}$ and why, in a recent meta-analysis, inhaled vasodilators in general failed to improve clinically relevant outcomes. $^{12}$

While we failed to show a benefit from the routine prophylactic application of inhaled iloprost in cardiac surgery, this should not invalidate the established use of nebulized $\mathrm{PGI}_{2}$ as a rescue treatment for perioperative $\mathrm{PH}$ and associated RV dysfunction. ${ }^{35}$

Lastly, we did not observe an increased incidence of adverse effects after perioperative iloprost inhalation. Prostacyclins are well-known inhibitors of platelet aggregation that can be used for therapeutic purposes. $^{36,37}$ Therefore, it has been argued that $\mathrm{PGI}_{2}$ nebulization could inhibit platelet aggregation and hence increase the risk of intra- and postoperative bleeding. In fact, $\mathrm{PGI}_{2}$ inhalation in cardiac surgical patients impairs platelet aggregation in vitro. ${ }^{38}$ The majority of clinical trials documented no impact on surgical bleeding though. $^{38,39}$ Our data support these latter findings, as iloprost inhalation was not associated with an increased incidence of re-thoracotomy for bleeding or hemorrhagic stroke.

After iloprost inhalation, a significant spill-over into the systemic circulation can reduce systemic vascular resistance and eventually arterial hypotension. ${ }^{32}$ Nevertheless, systemic vasodilating effects of inhaled iloprost are normally counteracted by a more pronounced effect on pulmonary vascular resistance and consecutive increases in cardiac output, ${ }^{9,32}$ which was also observed in our study. Hence, iloprost inhalation was not associated with arterial hypotension, which is underlined by the fact that both treatment groups did not differ notably with respect to vasopressor requirements.
We acknowledge that our study suffers from several limitations. First, the study was only powered for a single primary outcome. Hence, the majority of observations concerning secondary and safety outcomes should be interpreted with caution. Second, the use of rescue iloprost in the placebo group could have "diluted" the treatment effect and may confound the interpretation of the results. Nevertheless, the use of inhaled iloprost as rescue medication was virtually identical in both groups, most probably confirming the lack of effectiveness. Moreover, after eliminating the patients having received rescue iloprost from the statistical analysis, the primary outcome remained virtually unchanged (data not shown). Third, owing to the fact that the present study was a pragmatic clinical effectiveness trial, there was no ECC weaning protocol and no mandatory hemodynamic treatment algorithm. Details of patient management were not documented on the clinical record forms. Hence, we are unable to report intercentre differences in patient management. Nevertheless, we suggest that the primary outcome was not subject to significant intercentre variability in management. No difference in outcome could be detected when stratifying the primary analysis for the different centres $(P=0.35)$ or for the EuroSCORE and the centre $(P=0.37)$.

Also the performance of echocardiography was left at the discretion of the investigators. Detailed echocardiographic data were not documented in the case record forms (except for signs suggestive of $\mathrm{RV}$ failure), and echocardiography files were not centrally evaluated.

In conclusion, this prospective randomized controlled multicentre trial on the prophylactic inhalation of iloprost in patients undergoing high-risk cardiac surgery with ECC did not show a reduction in postoperative ventilation time and suggests neither a clinically meaningful benefit nor a clinically meaningful increased incidence of adverse events.

Acknowledgements The authors are indebted to Dr. rer. nat. Marion Seybold (Medical \& Management Services, Biburger Weg 6, 82205 Gilching, Germany) for her substantial work as a clinical research associate on this study.

Conflicts of interest Dr. Winterhalter: No conflicts of interest to declare; Dr. Rex has been consulting for Paion and Vifor and has received travel support and speaking honoraria from AirLiquide, B Braun, Bayer HealthCare, Biosyn, Edwards Lifesciences, Nordic Pharma, Orion Pharma, Schering, and Prostrakran. Dr. Rex has received a research grant from AirLiquide, Nordic Pharma, and Biosyn. Dr. Kienbaum has been consulting for Baxter and AirLiquide and received speaking honoraria from Orion Pharma. Dr. Kienbaum received a research grant from AirLiquide. Dr. Zwissler: No conflicts of interest to declare. Dr. Müller: No conflicts of interest to declare. Dr. Dongas: No conflicts of interest to declare. Dr. Kaufmann: No conflicts of interest to declare. Dr. Stoppe has received travel fees and speaking honoraria from Biosyn. 
Editorial responsibility This submission was handled by Dr. Hilary P. Grocott, Editor-in-Chief, Canadian Journal of Anesthesia.

Author contributions Michael Winterhalter and Steffen Rex helped conceive, design and conduct the study, acquired and coordinated the data, contributed to the statistical analysis, interpreted the data, and wrote and revised the manuscript. Christian Stoppe helped conduct the study, acquired and interpreted the data, and wrote and revised the manuscript. Peter Kienbaum helped conceive, design and conduct the study, acquired the data, and wrote and revised the manuscript. HansHelge Müller helped conceive and design the study, contributed to the statistical analysis, coordinated and interpreted the data, and wrote and revised the manuscript. Ines Kaufmann helped conduct the study, acquired and interpreted the data, and wrote and revised the manuscript. Herrmann Kuppe and Aristidis Dongas helped conceive, design and conduct the study, acquired and interpreted the data, and wrote and revised the manuscript. Bernhard Zwissler helped conceive, design and conduct the study, acquired and coordinated the data, contributed to the statistical analysis, interpreted the data, and wrote and revised the manuscript.

Sources of Funding This investigator-initiated trial was supported by Bayer Vital GmbH, Leverkusen, Germany (financial support and provision of the study medication; by Inspiration Medical, Bochum, Germany, and by Aerogen Ltd, Galway, Ireland (provision of nebulizers). Bayer Vital had no role in the design of the study, data collection and analysis, or the preparation of the manuscript. The company also had no responsibility for the conduct of the trial, had no access to the data, and did not control the decision to publish the results.

\section{References}

1. Winterhalter $M, \operatorname{Rex} S$, Stoppe $C$, et al. The clinical significance of intraoperative iloprost inhalation on outcome of high risk cardiac surgical patients: a multicenter randomized-controlled trial. Circulation 2016; 134: A13135.

2. Millar JE, Fanning JP, McDonald CI, McAuley DF, Fraser JF. The inflammatory response to extracorporeal membrane oxygenation (ECMO): a review of the pathophysiology. Crit Care 2016; 20: 387.

3. Humbert M, Lau EM, Montani D, Jais X, Sitbon O, Simonneau G. Advances in therapeutic interventions for patients with pulmonary arterial hypertension. Circulation 2014; 130: 2189208.

4. Dorman BH, Bond BR, Clair MJ, et al. Temporal synthesis and release of endothelin within the systemic and myocardial circulation during and after cardiopulmonary bypass: relation to postoperative recovery. J Cardiothorac Vasc Anesth 2000; 14: 540-5.

5. Tornberg DC, Angdin M, Settergen G, Liska J, Lundberg JO, Weitzberg E. Exhaled nitric oxide before and after cardiac surgery with cardiopulmonary bypass-response to acetylcholine and nitroglycerin. Br J Anaesth 2005; 94: 174-80.

6. Denault AY, Pearl RG, Michler RE, et al. Tezosentan and right ventricular failure in patients with pulmonary hypertension undergoing cardiac surgery: the TACTICS trial. J Cardiothorac Vasc Anesth 2013; 27: 1212-7.

7. Kirklin JK, Naftel DC, Pagani FD, et al. Sixth INTERMACS annual report: a 10,000-patient database. J Heart Lung Transplant 2014; 33: 555-64.
8. Denault AY, Bussières JS, Arellano $R$, et al. A multicentre randomized-controlled trial of inhaled milrinone in high-risk cardiac surgical patients. Can J Anesth 2016; 63: 1140-53.

9. Rex S, Schaelte G, Metzelder S, et al. Inhaled iloprost to control pulmonary artery hypertension in patients undergoing mitral valve surgery: a prospective, randomized-controlled trial. Acta Anaesthesiol Scand 2007; 52: 65-72.

10. Rex $S$, Devroe $S$. Anesthesia for pregnant women with pulmonary hypertension. Curr Opin Anaesthesiol 2016; 29: 273-81.

11. Harjola VP, Mebazaa A, Čelutkiene J, et al. Contemporary management of acute right ventricular failure: a statement from the Heart Failure Association and the Working Group on Pulmonary Circulation and Right Ventricular Function of the European Society of Cardiology. Eur J Heart Fail 2016; 18: 22641.

12. Elmi-Sarabi $M$, Deschamps A, Delisle $S$, et al. Aerosolized vasodilators for the treatment of pulmonary hypertension in cardiac surgical patients: a systematic review and meta-analysis. Anesth Analg 2017; 125: 393-402.

13. Rex S, Busch T, Vettelschoss M, de Rossi L, Rossaint R, Buhre W. Intraoperative management of severe pulmonary hypertension during cardiac surgery with inhaled iloprost. Anesthesiology 2003; 99: 745-7.

14. Winterhalter $M$, Simon A, Fischer $S$, et al. Comparison of inhaled iloprost and nitric oxide in patients with pulmonary hypertension during weaning from cardiopulmonary bypass in cardiac surgery: a prospective randomized trial. J Cardiothorac Vasc Anesth 2008; 22: 406-13.

15. Hoeper MM, Olschewski H, Ghofrani HA, et al. A comparison of the acute hemodynamic effects of inhaled nitric oxide and aerosolized iloprost in primary pulmonary hypertension. German PPH study group. J Am Coll Cardiol 2000; 35: 176-82.

16. Kisch-Wedel H, Kemming $G$, Meisner F, et al. The prostaglandins epoprostenol and iloprost increase left ventricular contractility in vivo. Intensive Care Med 2003; 29: 1574-83.

17. Rex $S$, Missant $C$, Claus $P$, Buhre W, Wouters PF. Effects of inhaled iloprost on right ventricular contractility, right ventriculovascular coupling and ventricular interdependence: a randomized placebo-controlled trial in an experimental model of acute pulmonary hypertension. Crit Care 2008; 12: R113.

18. Rex S, Missant $C$, Segers $P$, Rossaint $R$, Wouters PF. Epoprostenol treatment of acute pulmonary hypertension is associated with a paradoxical decrease in right ventricular contractility. Intensive Care Med 2008; 34: 179-89.

19. Zardi EM, Zardi DM, Dobrina A, Afeltra A. Prostacyclin in sepsis: a systematic review. Prostaglandins Other Lipid Mediat 2007; 83: 1-24.

20. Xiao CY, Hara A, Yuhki K, et al. Roles of prostaglandin I(2) and thromboxane $\mathrm{A}(2)$ in cardiac ischemia-reperfusion injury: a study using mice lacking their respective receptors. Circulation 2001; 104: $2210-5$

21. Searcy RJ, Morales JR, Ferreira JA, Johnson DW. The role of inhaled prostacyclin in treating acute respiratory distress syndrome. Ther Adv Respir Dis 2015; 9: 302-12.

22. Wittwer T, Franke UF, Ochs $M$, et al. Inhalative pre-treatment of donor lungs using the aerosolized prostacyclin analog iloprost ameliorates reperfusion injury. J Heart Lung Transplant 2005; 24 : 1673-9.

23. Wilkens $H$, Bauer $M$, Forestier $N$, et al. Influence of inhaled iloprost on transpulmonary gradient of big endothelin in patients with pulmonary hypertension. Circulation 2003; 107: 1509-13.

24. Lessiani G, Vazzana $N$, Cuccurullo $C$, et al. Inflammation, oxidative stress and platelet activation in aspirin-treated critical limb ischaemia: beneficial effects of iloprost. Thromb Haemost 2011; 105: 321-8 
25. Melby SJ, Moon MR, Lindman BR, Bailey MS, Hill LL, Damiano $R J J r$. Impact of pulmonary hypertension on outcomes after aortic valve replacement for aortic valve stenosis. J Thorac Cardiovasc Surg 2011; 141: 1424-30.

26. Lo $C$, Murphy $D$, Summerhayes $R$, et al. Right ventricular failure after implantation of continuous flow left ventricular assist device: analysis of predictors and outcomes. Clin Transplant 2015; 29: 763-70.

27. Sharma V, Rao V, Manlhiot C, Boruvka A, Fremes $S$, Wasowicz $M$. A derived and validated score to predict prolonged mechanical ventilation in patients undergoing cardiac surgery. J Thorac Cardiovasc Surg 2017; 153: 108-15.

28. Rady MY, Ryan T. Perioperative predictors of extubation failure and the effect on clinical outcome after cardiac surgery. Crit Care Med 1999; 27: 340-7.

29. Lassnigg A, Hiesmayr MJ, Bauer P, Haisjackl M; Workgroup on Postoperative Intensive Care of the European Society of Intensive Care Medicine; European Workgroup of Cardiothoracic Intensivists. Effect of centre-, patient- and procedure-related factors on intensive care resource utilisation after cardiac surgery. Intensive Care Med 2002; 28: 1453-61.

30. Olschewski H, Simonneau G, Galiè N, et al.; Aerosolized Iloprost Randomized Study Group. Inhaled iloprost for severe pulmonary hypertension. N Engl J Med 2002; 347: 322-9.

31. Gavra $P$, Nguyen $A Q$, Beauregard $N$, Denault $A Y$, Varin $F$. Highperformance liquid chromatography assay using ultraviolet detection for urinary quantification of milrinone concentrations in cardiac surgery patients undergoing cardiopulmonary bypass. Biomed Chromatogr 2014; 28: 1084-9.

32. Olschewski H, Rohde B, Behr J, et al. Pharmacodynamics and pharmacokinetics of inhaled iloprost, aerosolized by three different devices, in severe pulmonary hypertension. Chest 2003; 124: 1294-304.

33. Loh E, Stamler JS, Hare JM, Loscalzo J, Colucci WS. Cardiovascular effects of inhaled nitric oxide in patients with left ventricular dysfunction. Circulation 1994; 90: 2780-5.

34. Grossman NL, Fiack CA, Weinberg JM, Rybin DV, Farber $H W$. Pulmonary hypertension associated with heart failure with preserved ejection fraction: acute hemodynamic effects of inhaled iloprost. Pulm Circ 2015; 5: 198-203.

35. Lowson SM. Inhaled alternatives to nitric oxide. Crit Care Med 2005; 33: S188-95.

36. Radomski MW, Palmer RM, Moncada S. The anti-aggregating properties of vascular endothelium: interactions between prostacyclin and nitric oxide. Br J Pharmacol 1987; 92: 639-46.

37. Palatianos $G$, Michalis A, Alivizatos $P$, et al. Perioperative use of iloprost in cardiac surgery patients diagnosed with heparininduced thrombocytopenia-reactive antibodies or with true HIT (HIT reactive antibodies plus thrombocytopenia): an 11-year experience. Am J Hematol 2015; 90: 608-17.

38. Haraldsson A, Kieler-Jensen N, Wadenvik H, Ricksten SE. Inhaled prostacyclin and platelet function after cardiac surgery and cardiopulmonary bypass. Intensive Care Med 2000; 26: 18894.

39. Haché $M$, Denault A, Bélisle $S$, et al. Inhaled epoprostenol (prostacyclin) and pulmonary hypertension before cardiac surgery. J Thorac Cardiovasc Surg 2003; 125: 642-9.

Publisher's Note Springer Nature remains neutral with regard to jurisdictional claims in published maps and institutional affiliations. 